\title{
Perceptions of Using Smart Mobile Devices in Higher Education Teaching: A Case Study from Palestine
}

\author{
Khitam Shraim \\ Palestine Technical University- Kadoorie, Palestine \\ Helen Crompton \\ Old Dominion University, United States
}

\begin{abstract}
Smart mobile devices (SMDs), especially smartphones and tablets, are becoming increasingly ubiquitous among educators and students in Palestine. While their use is on the rise, many academics are not effectively incorporating this technology into their teaching, which may be attributable to their negative perceptions of these devices. This study therefore examined academics' perceptions of the value of integrating SMDs into their teaching activities. A questionnaire survey collected data from 56 academic staff of the Palestine Technical University - Kadoorie, eliciting perceptions of the physical attributes of SMDs, participants' self-efficacy, the pedagogical affordance of mobile devices and challenges to their use in teaching. The findings show that participants were still at the stage of actively experimenting with smartphones and iPads, trialing their use at different levels and for different purposes. In general, although participants were unaware of the full potential of their functionalities, they viewed positively the various pedagogical affordances of integrating these devices into their teaching activities. The most important affordances were linking formal and informal learning spaces by providing anywhere-anytime learning opportunities, and developing interest in the subject matter, thus making learning experience more enjoyable, meaningful, and accessible. The results also identify various challenges including lack of experience and knowledge, finding the time to design and implement such integration, and selecting appropriate apps for the content being taught. Participants also expressed concerns with the limited connectivity and unreliability of Wi-Fi and 3G/4G networks in Palestine.
\end{abstract}

Keywords: Higher education; Smart mobile devices; Mobile learning; Faculty perceptions

\section{Introduction}

Smart mobile devices (SMDs), particularly smartphones and tablets, are becoming increasingly ubiquitous among educators and students. Increasing advances in mobile technology, wireless communication networks, physical features of devices and high penetration usage will drive future trends in mobile learning (Johnson, 2011). By 2017 around $69.4 \%$ of world's population is expected to use mobile phones (Srivastava, 2014). Reflecting global trends, mobile device penetration in Palestine reached 75\% in 2012 (GSMA, 2013). Given the ready-at-hand availability of SMDs, it is reasonable to recognize the valuable affordance of these technologies to enhance the practice of teaching and learning in higher education (HE) in Palestine, as well as to meet the 
needs of a generation for whom mobile devices are becoming an integral part of their everyday lives.

In Palestine, there was rapid growth of e-learning approach across the HE institution. Almost all universities in Palestine are offering some type of online education and e-services. Students can register for their classes, exchange information, receive course messages from their instructors, search the library for books, access course materials, look up their grades, and stay updated on their academic and financial records. On the other hand, instructors post lecture notes and communicate with students via bulletin boards (Shraim, 2012). Most of these services are webbased computer applications that restrict the academic staff and students from accessing them anytime and anywhere (Atallah \& Abu Ghosh, 2015). Recently, many Palestinian universities have mobile applications initiatives. For example, Islamic University Gaza and Quds Open University applied Android Applications for displaying the courses' schedule and exams' schedule for students from anywhere and anytime, also notifying the students to student lectures' schedule and exams automatically, viewing the academic information and grades report ( Atallah \& Abu Ghosh, 2015).The Palestinian HE environment had the required infrastructure to utilize mlearning. The WiFi networks are available across most Palestinian universities (Alzaza, 2012). Nevertheless, special attention should be paid to teaching staff perceptions of using SMDs in higher education teaching, as they play a central role in successful implementation of m-learning.

Recent studies indicate that while technology is used increasingly, many teachers are not effectively incorporating it into their teaching (Groff \& Mouza, 2008; Levin \& Wadmany, 2008; Russell et al., 2007). This can be attributed to teachers' negative perceptions of technology (Crompton, 2013a). Academics' perceptions of mobile technologies significantly influence the effective implementation of mLearning (Handal et al., 2013; MacCallum \& Jeffrey, 2009). Therefore, if academic staffs are to enhance teaching and learning practice effectively by integrating emerging mobile technologies, they must understand their particular attributes, perceive self-efficacy in using them, have positive attitudes towards their pedagogical affordances and recognize challenges to implementing them in education. In Palestine, university instructors' views on integrating mobile technology into their teaching are rarely considered. Therefore, this research explores the perceptions of academic staff at the Palestine Technical University Kadoorie (PTUK) towards the integration of SMDs in teaching, focusing on the most popular devices in Palestine: Android phones, iPhones, and iPads.

\section{Literature Review}

Educators' perceptions of the value of integrating smart mobile devices to enhance teaching are paramount to the success of implementing mobile technological innovation in education (Handal et al., 2013; Marinakou \& Giousmpasoglou, 2014). A number of studies illustrate educators' perceptions of the functionalities, self-efficacy, pedagogical affordances and challenges of these devices (Archibald et al., 2014; Churchill et al., 2012; Handal et al., 2013; Kenny et al., 2012; Marinakou \& Giousmpasoglou, 2014; Mills et al., 2014; Pegrum et al., 2013; Sad and Goktas, 2013; Thomas \& O'Bannon, 2013; Woodill, 2013). 


\section{Functionality and Features of Mobile Devices}

SMDs are revolutionary in combining computing and communication features in a single mobile device (Khaddage, 2013). Their popularity arises from the mobility of the technology, of the learner and of learning, especially in the HE landscape (El-Hussein \& Cronje, 2010). Smartphones (e.g. iPhone, Android, BlackBerry, and Windows phones) and tablets (e.g. iPad, Galaxy, LePad, and Dell Streak) are portable, handheld devices with the processing power and memory capacity to run various applications and store data such as documents, pictures and videos. In addition to calls and messages, they offer e.g. internet access, cameras, global positioning systems (GPS), audio and video recorders, which can be valuable instructional tools (Woodill, 2013). SMDs also provide a wide range of interactive software applications (apps), either pre-installed or freely and cheaply available, to support web browsing, social media, communication, location-based functions, interactivity, media production, entertainment and so on. This makes SMDs highly customized, personalized platforms for communication, organization, social networking, information production, and content management (Khaddage \& Lattemann, 2013).

Thomas et al. (2013) surveyed 78 teachers to identify the cell phone features that they had used for school-related work. Of the 10 features identified, almost half reported using the camera, clock, alarm and timer (46.2\%), and e-mail and texting (42.3\%). Other features (Internet, calculator, apps, video recorder, and audio recorder, accessing social networks) were used less frequently. Thomas and O'Bannon (2013) studied 92 pre-service teachers' perceptions at Midwestern Liberal Arts University and found that the features of cell phones providing instructional benefits were the calculator (79.3\%), Internet (77.2\%), and the audio player (67.4\%). The features they believed to be the least useful were texting (82.6\%) and access to social networking (85.9\%).

Many researchers report that SMD use has so far been limited to social communication, navigation information and resources, whereas few users have regarded mobile learning as a core pedagogical activity (Bennett et al., 2008; Handle et al., 2013; Thompson, 2013). As devices continue to enter the market, new features and capabilities appear increasingly frequently (MacCallum \& Jeffery, 2009). Therefore, it is important to encourage faculty to be confident in exploring other SMD functions for use in teaching.

\section{Pedagogical Affordances}

The effective use of SMDs in education requires knowledge of their functionalities and how to use them, but teachers must also understand their pedagogical affordances (Mishra \& Koehler, 2006). Klopfer and Squire (2008) summarize these as portability, social interactivity (collaboration), context sensitivity (gathering real or simulated data), connectivity (to data collection devices, other handhelds, networks) and individuality.

More recently, Kearney and Maher (2013) explored mobile learning for pre-service teachers, who used their iPads to mediate their own professional learning, exploiting features of authenticity and personalization in both formal and informal settings. The participants captured out-of-class math phenomena, following up and discussing implications for their teaching. They also used their 
devices to facilitate an enhanced awareness of math in everyday contexts, then used this knowledge to develop rich, contextualized ideas for their own ICT-mediated math tasks. They exploited the iPad's potential to conveniently and spontaneously take notes, observe lessons and make multi-modal reflections. Finally, they trialed a range of iPad-supported math assessment techniques, involving the generation and annotation of new media. Khaddage and Lattemann (2013) studied the use of three mobile apps (e-Lecture-Producer, Dropbox and QR Code) by 26 second-year students on an e-commerce course at Sharjah Women's College. They found that mobile devices and apps can be used as a form of ubiquitous learning, allowing teachers and students to collaborate, communicate and learn together, bridging formal and informal learning.

A qualitative study of teachers' adoption of iPod and iPad smart devices was conducted in Australia by Pegrum et al. (2013). Mobile devices were seen as enhancing student motivation and engagement, with empirical evidence of improved student learning. Teachers perceived the potential of these devices to be used for both organizational and pedagogical purposes. There were particular benefits for students with special needs, including those requiring early intervention or struggling with the curriculum, and those with visual impairments or dyslexia, who could resize and reformat text, as well as using voice recognition and text-to-speech apps. Participants in a study by Handal et al. (2013) perceived the greatest potentials of mobile technology as facilitating anywhere-anytime learning, improving students' communication beyond the university walls and enhancing autonomous learning. Marinakou and Giousmpasoglou (2014) investigated the adoption of mLearning at four universities in the Kingdom of Bahrain. Most respondents (84.4\%) found that mobile devices were very important in facilitating collaborative learning and information retrieval, and in sharing resources, whereas the least important function was assessment.

\section{Faculty Attitudes and Self-Efficacy}

In addition to appreciating the functionalities of SMDs, faculty members need to be competent in using these devices. Mobile self-efficacy has been investigated in several contexts among both instructors and students (Kenny et al., 2012; MacCallum \& Jeffery, 2009; Yang, 2012). In general, these studies found that teachers with high self-efficacy in using technologies were more likely to integrate these tools into their teaching. Kenny et al. (2012) quantitatively assessed the selfefficacy of nursing faculty and students at a community college in western Canada related to their potential use of mobile technology. The median mobile self-efficacy score was $75 \%$, indicating that both faculty and students were highly confident in their use of mobile technologies and prepared to engage in mobile learning.

Yang (2012) investigated attitudes and self-efficacy among 58 second-year university students in Taiwan who used mobile devices for mLearning in an English class. Most were competent enough in using mobile devices to read the assigned texts, post questions, read and provide feedback to peers. Students also took environmental pictures and filmed authentic scenarios related to what they had learned in textbooks. They then shared their pictures and films via the mobile devices. In other words, they possessed high self-efficacy for mobile devices and would thus relate the authentic material to the learned material. 
A mixed-methods study by Bansavich (2011) investigated attitudes towards the potential use of iPads in HE. Forty faculty members at the University of San Francisco indicated that key advantages included the e-reader and electronic textbook capabilities, annotating and note-taking for meetings and classes, multimedia viewing and interactivity, mobile learning inside and outside the classroom, high levels of engagement in language learning, use in clinical settings, apps for the sciences, and strong potential for teacher-student and student-student interactivity. Walters (2011) suggests that portability and kinesthetic interaction help students to develop visual and spatial skills, boosting creativity, while teachers can easily use iPads collect assignments.

Sad and Goktas (2013) surveyed 1,087 pre-service teachers regarding their perceptions of the instructional value of laptops and mobile phones. Participants did not perceive mobile phones to be effective instructional tools, whereas Thomas et al. (2013) found that a slight majority of instructors did support the classroom integration of mobile phones, stating that they engage and motivate students. Further, Thomas and O'Bannon (2013) found that more than half of pre-service teachers identified anywhere-anytime learning opportunities, increased student engagement, opportunities for differentiation of instruction, increased communication, and increased student motivation as benefits of using cell phones in the classroom.

\section{Challenges}

Alongside these advantages, challenges to the integration of mobile technologies in teaching must also be considered. Many researchers indicate specific physical limitations of SMDs, such as small screens, limited battery time and frustratingly small keypads (Bansavich, 2011; Marinakou and Giousmpasoglou, 2014; Pegrum et al., 2013). Furthermore, the bring-your-own-device (BYOD) model presents a challenge of a different kind in terms of the standards and specifications of the devices permitted to be used in class and, in particular, to log into an institution's network, with all of the attendant implications for institutional policies as well as IT support (Traxler, 2010). Here, network speed, capacity and security are likely to become increasingly important (e.g. Melhuish \& Falloon, 2010; Traxler, 2010).

Khaddage (2013) argues that mLearning should not be restricted by brand, device or operating system; yet most apps currently in use are pure native apps developed for a particular device and operating system, thus unusable across multiple platforms. Moreover, according to Pegrum et al. (2013), the many available apps are often underpinned by information-transmission or behaviorist drill-and-practice approaches, thus of relatively limited value in social constructivist classrooms oriented towards problem solving and critical enquiry.

According to MacCallum and Jeffery (2009), although today's educators may be more familiar with technology in general, they still may not be fully prepared or able to integrate newer mobile technologies into their teaching. Various studies of mLearning implementation (e.g. Crompton, 2011; Handal et al., 2013; Pegrum et al., 2013) highlight educators' attitudes towards the use of mobile technology and their ability to understand its functionalities and affordances as significant constraints to its meaningful pedagogical integration. Educators see mobile technology as an inappropriate distraction for learners, promoting disruption and cheating (Khaddage and Lattemann, 2013; Thomas et al., 2013; Thomas and O'Bannon, 2013). Other ethical issues concern 
digital safety, privacy and surveillance, and the blurring of public-private boundaries (e.g. Pachler et al., 2010; Traxler, 2010).

Only 23 percent of the teachers surveyed by Pegrum et al. (2013) felt well prepared to integrate mobile technology into their instruction, while half of those surveyed by Handal et al. (2013) believed that they needed training. Educators therefore need training into how to incorporate these devices into content and to explore truly innovative uses (Melhuish \& Falloon, 2010; Pegrum et al., 2013). Training programs can also foster positive attitudes towards technology through a deeper understanding of its affordances, increased personal knowledge and greater confidence in its use (Crompton, in press).

Finally, weak institutional support can hinder effective integration (Shraim, 2012). Effective mobile learning environments need "strong institutional support, including the design of relevant resources in mobile format ... and technical support" (Sharples, 2007, p. 8).

\section{Research Questions}

The major purpose of this study is to investigate faculty's perceptions of the value of integrating smart mobile devices into their teaching. The main research questions are:

1. What attributes/physical features of smart mobile devices (smartphones/tablets) do faculty perceive as unique/useful for incorporation into their teaching activities?

2. What do faculty perceive as the pedagogical affordances of smartphones/tablets in enhancing teaching and learning?

3. To what extent do faculty perceive self-efficacy in integrating smartphones/tablets into various teaching activities?

4. In the context of Palestine, what do faculty perceive as the challenges to integrating smartphones/tablets into their teaching?

\section{Methods}

A quantitative descriptive method was used to investigate the perceptions of faculty members regarding the integration of smart mobile technologies in their teaching activities. A questionnaire was developed, based on literature related to mLearning. In addition to personal information, the questionnaire items addressed perceptions of the physical attributes of SMDs, self-efficacy, pedagogical affordances and challenges. There was a mix of question types, including four- and five-point Likert-scale items, checklists, and an open-ended question. The content validity of the questionnaire was assessed by two experts in the field of educational technology. Positive feedback was received and some changes were made to the instrument according to their suggestions. The reliability of the constructs was examined using Cronbach's alpha see Table 1. The invitation to complete the questionnaire was sent by the PTUK university email to 190 faculty members. The survey was conducted from $10^{\text {th }}$ of January 2015 through $5^{\text {th }}$ of February 2015. 
Table1. Reliability of the Constructs

\begin{tabular}{|l|c|c|}
\hline Constructs & Items & Cronbach's alpha \\
\hline Perceptions of the Physical Attributes of SMD & 11 & 0.81 \\
\hline Perceived Pedagogical Affordances of SMD & 10 & 0.83 \\
\hline Perceived Self-Efficacy in Using SMD & 13 & 0.86 \\
\hline
\end{tabular}

Findings

The following five subsections summarize the main results of the study, concerning first participants' information, then each of the four research questions: perceptions of the physical attributes of SMDs, self-efficacy, pedagogical affordances and challenges.

\section{Participants' information}

A total of 63 faculty members at PTUK participated in this study. Seven of the received responses were dropped because they were incomplete. Of the 56 responses, 30\% females and $70 \%$ males, representing various disciplines: $63 \%$ in sciences and $37 \%$ in humanities. Three-quarters were between the ages of 25 and 45 . Older individuals tended to decline to participate, perhaps being less attracted to technology and having less dependency on it. The majority of the 56 participants (91\%) owned a smartphone and only $9 \%$ owned a basic cell phone. Half had tablets and 43 owned multiple devices, including smartphones, iPads and digital cameras.

\section{Perceptions of the Physical Attributes of Smart Mobile Devices}

The perceived usefulness of the attributes of SMDs for teaching activities varied. Figure 1 shows that $81 \%$ of respondents found their most useful feature to be mobility in terms of internet connectivity and portability, helping students to learn anywhere at any time. Almost as many (79\%) felt that generic apps were useful or very useful. Other important features were audio/video (73\%), camera (71\%), storage (67\%) and messaging (63\%). Conversely, respondents did not consider the virtual assistant or GPS very useful features for students. Tracking the position of mobile devices is politically sensitive in a conflict area such as Palestine.

\section{Perceived Pedagogical Affordances of Smart Mobile Devices}

Participants were asked to rate on a 5-point Likert scale their agreement or disagreement with a set of statements on the pedagogical affordances of smartphones/tablets. The means for most responses were above the mid-point of 3 (Table 2). Overall, respondents had a positive perception of the affordances of mobile devices in their teaching. The strongest agreement was with the statement that the use of SMDs links formal learning with informal learning spaces by providing anywhere-anytime learning opportunities (mean=3.82). Another important affordance was to 
develop further interest in subject matter, making learning more enjoyable, meaningful and accessible (mean=3.79). The least important perceived affordance was to provide students with varied formative and summative assessments aligned with learning outcome (mean=2.34), and to promote student reflection using collaborative tools to clarify their conceptual understanding and thinking (mean=2.84).

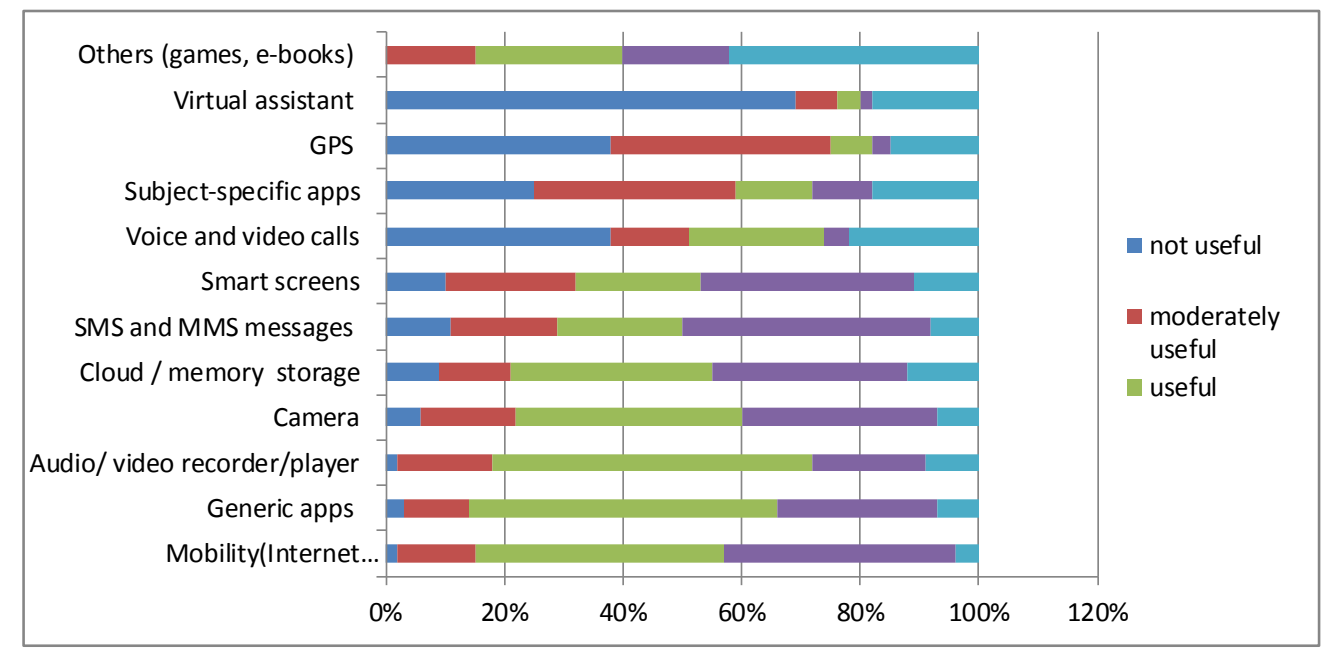

Figure 1. Perceptions of the Physical Attributes of Mobile Devices

Table 2. Perceived Pedagogical Affordances of SMDs

\begin{tabular}{|c|c|c|}
\hline Rank & Statements: “The use of smartphones/tablets in teaching...." & Mean \\
\hline 1. & $\begin{array}{l}\text {... links formal learning into informal learning spaces by providing } \\
\text { anywhere and anytime learning opportunities. }\end{array}$ & 3.82 \\
\hline 2. & $\begin{array}{l}\text {... develops further interest in subject matter, makes learning more } \\
\text { enjoyable, meaningful and accessible. }\end{array}$ & 3.79 \\
\hline 3. & $\begin{array}{l}\text {... provides a dynamic visualization of concepts to better } \\
\text { communicate ideas to students. }\end{array}$ & 3.56 \\
\hline 4. & $\begin{array}{l}\text {... facilitates educational management of marks, attendance, } \\
\text { calendar, reminders. }\end{array}$ & 3.53 \\
\hline 5. & $\begin{array}{l}\text {... engages students in exploring real-world issues and solving } \\
\text { authentic problems. }\end{array}$ & 3.48 \\
\hline 6. & $\begin{array}{l}\text {... personalizes learning activities and allows me to differentiate my } \\
\text { lessons to address students' diverse learning styles. }\end{array}$ & 3.27 \\
\hline 7. & $\begin{array}{l}\text {... keeps me up to date with pedagogical innovation and new trends } \\
\text { in instructional strategies to meet the needs of } 21^{\text {st }} \text {-century } \\
\text { learners. }\end{array}$ & 3.07 \\
\hline 8. & $\begin{array}{l}\text {... enriches my teaching experience through social collaboration with } \\
\text { colleagues and professional associations. }\end{array}$ & 2.98 \\
\hline 9. & $\begin{array}{l}\text {... promotes student reflection, using collaborative tools to clarify } \\
\text { their conceptual understanding and thinking. }\end{array}$ & 2.84 \\
\hline 10. & $\begin{array}{l}\text {... provides students with varied formative and summative } \\
\text { assessments aligned with learning outcomes. }\end{array}$ & 2.34 \\
\hline
\end{tabular}




\section{Perceived Self-Efficacy in Using Smart Mobile Devices}

Participants were asked to assess their own ability to use different functions of SMDs, rating themselves as basic, intermediate, experienced, or professional. In general, participants were confident in using several basic functionalities in their teaching. The highest percentages assessed themselves as professional in communicating with students through text messages and email $(56 \%)$, in using a camera (51\%) and in networking via social sites (47\%). Conversely, many described themselves as having only basic skill in connecting a mobile to a projector (66\%), constructing multimedia objects (62\%) and downloading a subject-specific app that aligns with learning outcomes (41\%).

\section{Perceived Challenges}

The survey listed several challenges that might arise when integrating SMDs into teaching. The greatest challenges for respondents were wireless network limitations $(93 \%)$ and their own lack of experience or knowledge of how to use SMDs in lessons (88\%). Over $80 \%$ had concerns about finding the time to design and implement their plans and about exploring appropriate apps to match the content being taught. The three least important challenges concerned networking with professional associations (59\%), hardware limitations (50\%) and language (23\%). PTUK learners tend to prefer mobile apps in Arabic, as this is the language of study.

Table 3. Perceived Challenges

\begin{tabular}{|c|l|c|c|}
\hline Rank & \multicolumn{1}{|c|}{ Challenges } & Frequency & $\%$ \\
\hline 1. & Wireless network limitation (Wi-Fi, 3G, 4G) & 52 & $92.9 \%$ \\
\hline 2. & Lacking in experience or knowledge of how to integrate mobile technologies in & 49 & $87.5 \%$ \\
\hline 3. & Finding the time to design and implement my plan. & 46 & $82.1 \%$ \\
\hline 4. & Exploring appropriate apps that match the content being taught. & 45 & $80.4 \%$ \\
\hline 5. & BYOD: Devices use different platforms. & 42 & $75.0 \%$ \\
\hline 6. & Mobile app software limitations (limited functionality, e.g. cross-platform.....). & 41 & $73.2 \%$ \\
\hline 7. & Teachers' beliefs (distracting, cheating, resistance to change....). & 40 & $71.4 \%$ \\
\hline 8. & Getting adequate technology support. & 38 & $67.9 \%$ \\
\hline 9. & Getting institutional support (funding, infrastructure, policy, ...). & 37 & $66.1 \%$ \\
\hline 10. & Cost of devices, apps, training. & 36 & $64.3 \%$ \\
\hline 11. & Networking with professional associations. & 33 & $58.9 \%$ \\
\hline 12. & Mobile device hardware limitations (screen size, screen resolution, keyboard, & 28 & $50.0 \%$ \\
\hline 13. & Other (language...) & 13 & $23.2 \%$ \\
\hline
\end{tabular}

\section{Discussion}

Factors affecting the successful integration of mobile devices include the pedagogical beliefs of educators as well as their skills and knowledge (Thomas \& O'Bannom, 2013). The participants identified several pedagogical affordances of SMDs that would be useful to enhance their teaching 
practices. It is widely believed that by generating content from real-world contexts, SMDs provide learners with authentic tasks, keep them active and support teachers in creating more engaging experiences (Pegrum et al., 2013). Half of participants agreed that SMDs helped them to engage students in exploring real-world issues and solving authentic problems. Smartphones/tablets offer learners various ways to connect the curriculum with real life and to engage through text, voice, image, and video. For example, teachers of English as a second language can ask learners to use their mobiles to access various news sites or podcasts, to listen or read current reports of global interest on e.g. Ebola, sport, economics, finance, technology, science or education, then to prepare a two-minute talk using the VoiceThread app to express their own opinions. This encourages higher-level thinking skills and improves students' reading, listening and speaking skills. Thus, SMDs support teachers in ways consistent with the above assertion of Pegrum et al. (2013), creating a more meaningful learning experience because learners take more responsibility for their learning and feel as though they are contributing in unique ways.

Mobile devices can play an important role in the informal learning environment, as they can be used for communication, collaboration, gathering and sharing of information (Khaddage \& Lattemann, 2013). $72 \%$ of participants agreed that SMDs help to link formal learning into the informal learning spaces; portability and internet connectivity are significant in creating "ubiquitous learning" (Murphy, 2011). The slim, lightweight devices are easily carried anywhere, while Internet connectivity through built-in Wi-Fi and 3G/4G networks allows learning content to be accessed anywhere at any time (El-Hussein \& Cronje, 2010). However, mobility needs reliable networks. 93\% of participants expressed concerns with the limited connectivity and unreliability of Wi-Fi and 3G/4G networks in Palestine. While the Internet is commonplace in developed countries today, access remains patchy in developing countries. In Palestine, for example, free 3G/4G webbrowsing is not available, due to Israel's refusal to release the frequencies required. $3 G / 4 G$ is an important requirement for the successful implementation of mobile learning, which is difficult to meet at present (Shraim, 2014).

$71 \%$ of participants found built-in cameras useful. Teachers can motivate learners to take images and video of real life in diverse locations and to share this user-generated content digitally with their peers. learners can also collect information using the SMD's camera/microphone, write notes, discuss findings through instant messaging or share them on social apps. This affordance is particularly important given the political restrictions on movement in Palestine, whereby many young people are unable to visit various locations such as Jerusalem or Gaza. SMDs can help teachers to overcome such limitations and to bridge formal and informal reality for students who value anytime, anywhere, on-demand, flexible learning.

Personalized learning environments are important for a generation who expect learning to be "just in time, just enough, and just for me" (Rosenberg 2001). Half of participants agreed that SMDs helped them to personalize learning activities and differentiate their lessons to address students' diverse learning styles. Teaching materials can be customized to learners' learning style, location, time and activity (Isabwe, 2014). Portability, connectivity and social networks allow learners to access material and learn individually, at their own pace and style, "just in time". Another important aspect of personalized student learning is the wide choice of apps and resources available to learners via their SMDs, but for academics, this is a challenging process. $80 \%$ of participants expressed concerns in selecting apps appropriate to learners and to the content being 
taught. Academics need to understand whether to use a native app or a web app, and at what level; to use apps in content transmission, behaviorist apps to reinforce learning, or constructivist apps to promote students' creativity and higher-order thinking (Oakley et al., 2012). Pegrum et al. (2013) conclude that it is important that teachers have access to valid and usable criteria by which to evaluate educational apps for a range of purposes, and access to a database of quality apps, checklists or rubrics; such tools need to be developed and widely disseminated to help teachers to judge quality and appropriateness.

Students also come to the university with SMDs; therefore, unlike centrally provided laptops or computers, the BYOD model creates personalized learning on different platforms, rather than a one-size-fits-all roll-out of a particular device (Isabwe, 2014). However, BYOD was perceived as a constraint to effective integration of SMDs by three-quarters participants. Implementing different apps on different devices and platforms (e.g. iOS and Android) is difficult and requires careful planning. Similarly, Pegrum et al. (2013) found that mobile devices available among students varied from SMDs to non-smart mobiles. Quinn (2000) suggests that a mobile learning solution must work for a wide range of devices. Mobile learning models should be capable of deviceindependent delivery of learning content and learning management.

Three-quarters of respondents agreed that SMDs help faculty to develop further interest in subject matter, make learning more enjoyable, meaningful and accessible. Features of mobile technology affect content delivery, time and location of engagement, and collaborative opportunities (Crompton, 2013b). Instructors can deliver learning material in different formats and learners can interact with it more easily and enjoyably, using e.g. highlighting, bookmarking or note-taking, then share with peers using touch, movement and even facial expressions. Over half of participants considered smart screens useful for interaction, visualization, annotation and zooming. According to Johnson et al. (2010), human-computer interactions are moving away from the standard keyboard and mouse, towards more intuitive, gesture-based communication systems responsive to natural human movements. To improve learning and maintain motivation, activities should be fun; Isabwe (2014) refers to the "gamification" of mobile learning. Games were considered useful by $43 \%$ of participants. Mobile devices have multiple features to support gaming applications; this opportunity should be seized, especially for less motivated students.

A specific affordance of mobile devices is to help faculty to provide a dynamic visualization of concepts to better communicate ideas to students. More than $62 \%$ of respondents agreed. Many apps for analyzing and visualizing complex datasets are becoming more readily available. Educators see great potential for apps that allow science students to manipulate data and process statistics, deepening their understanding of complex relationships and concepts (Johnson et al., 2010). For example, infographic apps are increasingly important, combining different types of video and audio to capture rich experiences. It is widely believed that visualization gives a better representation of data that enables learners to better understand and interpret information than inputs in figures and words; this can improve both attention and comprehension.

The results also indicated that half of participants perceived a technological challenge in the limited usability and physical attributes of mobile devices, such as screen size, memory, battery life and storage capacity, especially for basic devices. This finding is supported by other research. For example, Pegrum et al. (2013) found that screens can be too small, especially for reading 
pages of text. Similarly, Archibald et al. (2014) report negative perceptions of typing data into small devices; they suggest that any electronic data-input form should be designed to collect the most valuable information with minimal effort. According to Texlar (2010), these devices are not designed for educational purposes. However, technical specifications change rapidly and the new generation of SMDs have many refined functionalities (Shraim, 2014).

Nearly two-thirds of participants highlighted the usefulness of SMDs in facilitating educational management of grades, attendance, calendars, reminders, registration etc. This result is consistent with other research including Pegrum et al. (2013), who found that mobile technology could be used to monitor individual progress by keeping track of which courses had been administered to particular students.

A significant affordance of SMDs, perceived by only $25 \%$ of participants, is to provide students with varied formative and summative assessments aligned with learning outcomes. Various mobile apps can support formative assessment by means of frequent multiple choice tests of students' performance and progress, enabling teachers to make changes in instruction for those experiencing difficulty. For example, teachers can use i>clickers (a remote device or a web-based multiple choice voting system) and Poll Everywhere (a web-based multiple choice voting system) to assess students' understanding in real time, analyzing misconceptions, displaying responses instantly for discussion, providing formative data to guide instruction, and efficiently administering and scoring quizzes. Teachers can also present a problem or case study to the class, followed by multiple-choice answers using i>clickers. This affordance was perceived as valuable by relatively few respondents, not only because assessment apps are more appropriate for formative than summative assessment, but perhaps also because of institutional policy: security, access control and privacy issues arise, as mobile devices may use a multitude of network access technologies. Assessment must change, along with teaching methods, tools and materials.

The affordances of mobile technology facilitate communication and interaction in the community of learners. Synchronous and asynchronous collaboration is achieved through many communication apps such as email, SMS, file sharing, and social networking (Isabwe, 2014). Communication by texting was perceived as useful by around of $63 \%$ of participants, being simple, cheap and almost universally accessible. SMS applications can help faculty to engage learners anywhere and anytime, encourage interaction, and facilitate social learning (Elias, 2011). Although they are limited to 160 characters, SMS applications can work on any mobile device almost instantaneously (e.g. for sending timely alerts). Learners may also interact with each other using instant messaging programs on SMDs. By contrast, Thomas and O'Bannon (2013) found that texting was perceived as least useful, perhaps because their respondents associated it with classroom distraction. Only $27 \%$ of PTUK participants saw voice and video calls as a useful means of communication between staff and students. This may be because voice calls are expensive in Palestine, while free calls through social networking apps need an Internet connection, which is not always available.

Mobile learning supports a social-constructivist pedagogy, with particular emphasis on students' responsibility and ownership of learning. Students working in collaborative groups are more active learners and more accountable to the group for learning (Pegrum et al., 2013). Only 35\% of participants agreed that mobile technologies help faculty to promote student reflection using 
collaborative tools to clarify students' conceptual understanding, thinking and generating content. There are many apps that can help students reflect on their learning, such as VoiceThread and Asana. Students are often strongly motivated to post their reflections, encourage collaborative learning, and build skills in higher-level thinking, oral communication, selfmanagement and leadership. The low score may reflect teachers' concerns about Arab culture regarding female privacy.

Many participants (41\%) agreed that mobile technologies enrich teachers' experience through social collaboration with colleagues and professional associations. Social networking apps such as Facebook, Twitter and LinkedIn allow faculty to find other professionals with common interests, discuss pedagogical issues, and share experience. $45 \%$ of participants also agreed that mobile technologies help faculty to keep up to date with pedagogical trends and innovation to meet the needs of $21^{\text {st }}$-century learners. Changes are happening and teachers should run to keep up with them. More effort is needed to develop activities that satisfy learners' needs. Therefore, teachers should adapt to rapid technological change, matching students' behavior and learning preferences. The findings also indicated that $82 \%$ of participants expressed concerns with finding the time to design and implement their plans. Teaching load in the Palestinian universities is 12 credit hours and majority of teachers prefer to take overload due to the low salary. It is timeconsuming to develop new approaches and resources, explore appropriate apps, and keep up-todate with innovations, adding to teachers' workload. This result is consistent with Handal et al. (2013) and Pegrum et al. (2013), who emphasize the importance of networking as a platform for professional development. This is a sustainable model which could encourage collaboration, save time and energy, and alleviate academic workload (Handal et al., 2013; Oakley et al., 2012).

While almost all respondents used SMDs in daily life, most lacked experience and knowledge of integrating them into their teaching activities. This finding is consistent with many studies of mobile learning implementation (Handal et al., 2013; Pegrum et al., 2013; Sad \& Goktas, 2013; Yang 2012). Faculty still did not understand the concept of mLearning and the pedagogical and technological considerations of integrating mobile technology into their teaching. This indicates that academics need to know when to use mobile technology, when mobile apps are suitable for integration into specific activities, and which content is most effectively presented to learners on small mobile screens. They must also understand the just-in-time nature of mLearning. According to Stayton (2011), mobile solutions are appropriate in creating bite-sized chunks of information, which is especially critical when using devices with very small screens. Therefore, it is important to train faculty in how to integrate these devices, in terms of both content and pedagogy (Mishra \& Koehler, 2006).

\section{Opportunities of Integrating SMDs in HE Teaching}

Participants were questioned about their interest in integrating SMDs into their teaching in the future. Only $25 \%$ were very interested in doing so, $40 \%$ somewhat interested and $35 \%$ not interested. Handal et al. (2013) measured the degree of adoption of mobile learning devices among academic staff at an Australian university at three on a six-point scale: academics were beginning to understand the process of using mobile technology and to identify specific tasks for which might it be useful. Marinakou and Giousmpasoglou (2014) found that three-quarters of 
respondents believed that mLearning would become an integral part of mainstream HE within five years. However, it cannot be assumed that teachers will automatically be able to use these devices (Johnson et al., 2010). Faculty still lack confidence, such as in using mobile apps to construct multimedia objects embedding pictures and animations, or in connecting their mobile devices to projectors. The necessary training should be easy to provide, as unlike computers, mobile devices are readily used without advanced technological skills. According to Khaddage and Zeidan (2012), the rapid development of mobile devices and their applications can simplify the process of integration into teaching and learning for non-technical users of all educational backgrounds. Pegrum et al. (2013) report that in some schools, teachers and other staff have successfully learnt SMD competence alongside and from students.

Another perceived challenge identified by $71 \%$ of participants was teachers' own beliefs. Resistance to changes in teaching practice was observed by Khaddage and Zeidan (2012), who reports that older teachers lack confidence in using these devices, seeing them as a distraction (Thompson, 2013), or as potential tools for cheating (Sad \& Goktas, 2013). Teachers need both the pedagogy and the time to think about how to change their practices to incorporate SMDs. Technology provides both a challenge and an opportunity for us to rethink what we are doing and how we are doing it.

In order to use SMDs effectively in their teaching, academics need to have a positive attitude towards mobile technology and to keep up-to-date with pedagogical innovations, thus meeting the demands of young learners to connect with their peers and teachers via SMS, voice/video calls, Facebook, Skype, Twitter, YouTube, etc. It is now important to have leaders and key teachers in universities who have an interest in implementing mobile handheld technologies, to act as role models and provide support to other teachers who will share their enthusiasm for the use of SMDs (Oakley et al., 2012).

Finally, institutional support is important to successful implementation of mobile learning. Twothirds of participants perceived poor institutional support as a barrier to adopting mLearning. Similarly, Marinakou and Giousmpasoglou (2014) highlight the need for institutional support including investment in infrastructure, promoting the adoption of new teaching practices, training staff, and developing clear policy. The use of SMDs in the classroom is banned in Palestine. To be widely adopted, mobile technology must be part of a comprehensive and systematic effort to change education policy (Handal et al., 2013).

\section{Conclusion}

With the growing use of SMDs among educators and learners in Palestine, this study has investigated faculty perceptions of using these devices for meaningful instruction. The findings show that while mobile learning (mLearning) is still at an experimental stage in Palestine, respondents had positive perceptions of the affordances of SMDs in their teaching. SMDs offer much functionality and new opportunities in the evolution of technology-enhanced learning, 81\% of respondents found their most useful feature to be mobility in terms of internet connectivity and portability, helping students to learn anywhere at any time. 
Participants identified several pedagogical affordances of SMDs that would be useful to enhance their teaching practices. The most important affordances were linking formal and informal learning spaces, and developing interest in the subject matter, thus making learning more enjoyable, meaningful, and accessible. Half of participants also agreed that SMDs helped them to engage students in exploring real-world issues and solving authentic problems. Smartphones/tablets offer learners various ways to connect the curriculum with real life and to engage through text, voice, image, and video.

Despite the high percentage of smartphone ownership, the study found that faculty were largely still unaware of the full advantages of the newly released SMD functionalities for their teaching, and indeed in daily life, including basic functions such as voice calling, photography, Internet access and social networking. Therefore, they should become familiar with these basic functions and be encouraged to explore more advanced ones for use in teaching. The results also identify various challenges. The greatest challenges for respondents were wireless network limitations $(93 \%)$ and their own lack of experience or knowledge of how to use SMDs in lessons (88\%). Over $80 \%$ also had concerns about finding the time to design and implement their plans and about exploring appropriate apps to match the content being taught.

In order to take full advantage of SMDs in their teaching, faculty must be familiar with how to use them and must understand their affordance and how to incorporate their functionalities into teaching activities. The results also identify and the need for institutional support to invest in academics' professional development and training in technology, in order to enhance the perception of mLearning in higher education in Palestine.

The limitations of this study include the small and limited sample of faculty from a single Palestinian university. Further research might focus on using the TPACK model to provide faculty with an understanding of the integration of subject content, pedagogical techniques, and mobile technological affordances. There is also a need to develop a set of principles to guide faculty in selecting appropriate apps while designing and applying mobile technologies.

\section{References}

Atallah, R. \& Abu Ghosh, M. (2015). Mobile cloud computing: Academic services for Palestinian higher education institutions (MCCAS). International Journal of Engineering Research and General Science, 1(3), 22-27.

Alzaza, N.S.(2012). Opportunities for utilizing mobile learning services in the Palestinian Higher Education. International Arab Journal of e-Technology, 2(4), 216-222.

Bennett, S., Maton, K., \& Kervin, L. (2008). The "digital natives" debate: A critical review of the evidence. British Journal of Educational Technology, 39(5), 775-786.

Churchill, D., Fox, B., \& King, M. (2012). Study of affordances of ipads and teachers' private theories. International Journal of Information and Education Technology, 2(3), 251-254. 
Crompton, H. (2013a). A historical overview of mobile learning: Toward learner-centered education. In Z. L. Berge \& L. Y. Muilenburg (Eds.), Handbook of mobile learning (pp. 3-14). Florence, KY: Routledge.

Crompton, H. (2013b). Mobile learning: New approach, new theory. In Z. L. Berge \& L. Y. Muilenburg (Eds.), Handbook of mobile learning (pp. 47-57). Florence, KY: Routledge.

El-Hussein, M. O. M. \& Cronje, J. C. (2010). Defining mobile learning in the higher education landscape. Educational Technology \& Society, 13(3), 12-21.

GSMA (2013). Arab states mobile observatory 2013 report. Retrieved on 6 March 2015 from http://www.gsma.com/publicpolicy/wpcontent/uploads/2012/03/GSMA_MobileObservator y_ArabStates2013.pdf

Handal, B., MacNish, J., \& Petocz, P. (2013). Academics adopting mobile devices: The zone of Haythornthwaite (Eds.). The Sage handbook of e-learning research (pp. 221-247). London: Sage.

Isabwe, G.M.N. (2014). Mobile learning: Learning supported by mobile technology based tools. Retrieved on 6 March 2015 http://ufbutv.com/2014/03/16/mobile-learning-learningsupported-by-mobile-technology-based-tools/

Johnson, L., Levine, A., Smith, R., \& Stone, S. (2010). The 2010 horizon report. Austin, TX: The New Media Consortium.

Johnson, L., Smith, R., Willis, H., Levine, A., \& Haywood, K. (2011). The 2011 horizon report. Austin, TX: The New Media Consortium.

Kearney, M. \& Maher,D. (2013). Mobile learning in maths teachers education: Using iPads to support pre-service teachers' professional development. Australian Educational Computing, 27(3), 76-84.

Khaddage, F. \& Zeidan, F. (2012, September). iPad in higher education, ready or not? A college case study in the Middle East. Proceeding of ICL (Interactive Collaborative Learning) Conference, Villach, Austria.

Looi, C. K., Seow, P., Zhang, B. H., So, H. J., Chen, W. L., \& Wong, L. H. (2010). Leveraging mobile technology for sustainable seamless learning: a research agenda. British Journal of Educational Technologies, 41(2), 154-169.

Marinakou, E. \& Giousmpasoglou, C. (2014, March). M-learning in higher education in Bahrain: The educators' view. Proceedings of the, HBMeU Congress 2014: Leading transformation to sustainable excellence. Dubai, UAE.

MacCallum,K. and Jeffrey,L. (2009). Identifying discriminating variables that determine mobile learning adoption by educators: An initial study. Proceedings of ascilite:" Same places, different spaces", Auckland 2009.

Melhuish, K. \& Falloon, G. (2010). Looking to the future: M-learning with the iPad. Computers in New Zealand Schools: Learning, Leading, Technology, 22(3), 1-15.

Mills, L., Knezek, G., \& Khaddage, F. (2014) Information seeking, information sharing, and going mobile: Three bridges to informal learning. Computers in Human Behavior, 32(2) 324-334. 
Mishra, P. \& Koehler, M. (2006). Technological pedagogical content knowledge: A new framework for teacher knowledge". Teachers College Record, 108(6), 1017-1054.

Murphy, G.D. (2011). Post pc devices: A summary of the early iPad technology adoption in tertiary environments. E-Journal of Business and Scholarship of Teaching, 5(1), 18-32.

Pachler, N. (2009). The LMLG socio-cultural ecological approach to mobile learning. London: LMLG WLE Centre.http://www.londonmobilelearning.net/downloads/LMLG_SCEA_2009.pdf

Pegrum, M., Oakley, G., \& Faulkner, R. (2013). Schools going mobile: A study of the adoption of mobile handheld technologies in Western Australian independent schools. Australasian Journal of Educational Technology, 29(1), 66-81.

Quinn, C. (2000). Mobile learning: Mobiles, wireless, in-your-pocket learning. LiNEZine. Retrieved on 6 March 2015 from http://www.linezine.com/2.1/features/cqmmwiyp.htm

Rosenberg, M. J. (2001). E-learning: Strategies for delivering knowledge in the digital age. New York: MacGraw-Hill.

Russell, M., O'Dwyer, L. M., Bebell, D., \& Tao, W. (2007). How teachers' uses of technology vary by tenure and longevity. Journal of Educational Computing Research, 37, 393-417.

Sad, S.N. \& Goktas, O. (2013). Preservice teachers' perceptions about using mobile phones and laptops in education as mobile learning tools. British Journal of Educational Technology, 45(4) 606-618.

Sharples, M., Taylor, J.,\& Vavoula, G. (2007). A theory of learning for the mobile age. In R. Andrews \& C. Haythornthwaite (Eds.), The Sage handbook of e-learning research (pp.221247). London: Sage.

Shraim, K. (2012) Moving towards e-learning paradigm: Readiness of higher education institutions in Palestine. International Journal on E-Learning, 11(4), 441-463.

Shraim, K. (2014) A case study of mobile technology-enabled English language learning: The Amazon kindle e-reader initiative in Palestine. International Journal of Interactive Mobile Technologies, 8(3), 25-31.

Srivastava, A. (2014). 2 billion smartphone users by 2015: 83\% of Internet usage from mobiles. Retrieved on 6 March 2015 from http://dazeinfo.com/2014/01/23/smartphone-usersgrowth-mobile-internet-2014-2017/

Stayton, L. (2011). Mobile learning: Look before you leap. Retrieved on 6 March 2015 from https://www.td.org/Publications/Newsletters/Learning-Circuits/Learning-CircuitsArchives/2011/06/Mobile-Learning-Look-Before-You-Leap

Thomas, K. \& O'Bannon, B. (2013). Cell phones in the classroom: Preservice teachers' perceptions. Journal of Digital Learning in Teacher Education, 30(1), 11-20.

Thompson, P. (2013).The digital natives as learners: Technology use patterns and approaches to learning. Computers and Education, 65, 12-33.

Traxler, J. (2010). Will student devices deliver innovation, inclusion, and transformation? Journal of the Research Center for Educational Technology, 6(1), 3-15. 
Walters, E. A. ( 2011). Will the iPad revolutionize education? Retrieved on 6 March 2015 from http://www.iste.org/Libraries/Leading_and_Learning_Docs/May-2011-Point-

Counterpoint.sflb.ashx

Winters, N. (2006). What is mobile learning? In M. Sharples (Ed.), Big issues in mobile learning: Report of a workshop by the Kaleidoscope network of excellence mobile learning initiative. University of Nottingham. England.

Woodill, G. (2013). The unique affordances of mobile learning understand how to leverage them prior to design and development. Retrieved on 6 March 2015 from http://floatlearning. com/ 2013/11/the-unique-affordances-of-mobile-learning/

Yang, S.H. (2012). Exploring college students' attitudes and self-efficacy of mobile learning. The Turkish Online Journal of Educational Technology, 11(4), 148-154.

Correspondence: Khtam Shraim, Assistant Professor, Department of Educational Technology, Palestine Technical University-Kadooire, Tulkarm, Palestine 